\title{
CUSTOMER SERVICE MANAGEMENT IN WESTERN \\ AND CENTRAL EUROPE: A CONCURRENT VALIDATION \\ STRATEGY IN ENTREPRENEURIAL FINANCIAL \\ INFORMATION SERVICES ORGANIZATIONS
}

\author{
Shawn M. Carraher, Ph.D. \\ Cameron University \\ Lawton, OK \\ Sarah C. Carraher \\ Consolidation Enterprises \\ Lawton, $\mathbf{O K}$ \\ Alma Mintu-Wimsatt, Ph.D. \\ Texas A \& M University - Commerce \\ Commerce, $\mathbf{T X}$
}

\begin{abstract}
The purpose of the present study was to test whether or not a biodata inventory could be used to measure service orientation within global entrepreneurial organizations in Western and Central Europe. A concurrent validation strategy was conducted consistent with the methodology previously presented by Schoenfeldt (1999). Within the samples of 403 and 295 non-American employees, the service orientation ratings were highly correlated with four scales: "Extroversion," "Openness to experience, " "Conscientiousness, " and "Agreeableness" and not significantly correlated with "Emotional Stability." The findings suggest that for organizational employee development and selection, service orientation may be effectively measured by an instrument such as this one and therefore potentially improve customer service management systems.
\end{abstract}

\section{Introduction}

Perceived customer service is often the determining factor in the initial purchase and/or repeat purchase of products. Positive customer service experiences drive customer satisfaction that subsequently affects the level of customer satisfaction. On the other hand, negative experiences reinforce customer dissatisfaction. A dissatisfied customer may become an economic liability to the organization, and worst, a critic of the products and services provided (Carrier, 1999; Waldman \& Gopalakrishnan, 1996).

The image of the organization in the mind of an individual consumer is often produced by a series of possible interactions with a finite number of [organi- 
zation's] employees. As a result, firms often attempt to shape their image with customers by managing the types of behaviors employees display (Becherer \& Maurer, 1999; Hipkin, 2000; Martin, 2000; O'Gorman \& Doran, 1999). This is because firms that emphasize higher levels of customer service report higher profitability, return on sales, return on investments, return on assets, and profit growth than those reporting less emphasis on customer service by the individual employees (Wright, Pearce, and Busbin, 1997). In fact, McWilliams, Van Fleet, \& Wright (2001) have argued that organizations may gain a global competitive advantage through the strategic use of their human resources.

To the extent that an organization's success depends on effective customer relations, the customer service employee plays a vital boundary spanning role for the organization (Robertson, 1995). The literature suggests that the nature of these front-line service jobs is uniquely demanding. Indeed, the social and emotional skills required of these employees are quite intense (Carraher \& Hart, 1995; Hui, Lam, \& Schaubroeck, 2001; Pugh, 2001). While customers may typically have as few as one or two service encounters daily; service employees may have to deal with several hundred customers or potential customers each day. More importantly, many of these customers have complaints about the organization's products and/or services. For employees of small to medium size businesses, the situation may be worse since nearly all employees may have normal contact with customers on a daily basis (O'Gorman \& Doran, 1999; Zinger, LeBrasseur, \& Zanibbi, 2001).

Because the social interaction and boundary spanning aspects of service jobs may demand nontechnical and noncognitive skills, these may be difficult to measure for many employees. This is particularly true for entry-level jobs where costly assessment techniques are rarely utilized (Mitchell, 1997). Consequently, other means of assessing skill sets necessary for customer service employees are often sought.

This study offers an alternative means of evaluating employees' service orientation. In particular, the current authors test whether a biodata inventory could be used to measure the service orientation construct across multiple cultures. Biodata information from employees of multinational entrepreneurial financial information services organizations was evaluated. Because of the size and nature of the organization's core business, the boundary spanning role of most employees are expected to be critical to the firm's success.

The remainder of this paper consists of four major sections. The first section lays the theoretical foundation for study. The second section discusses the methodology used in the study. Next, we report the results of the statistical analyses. The final section contains our conclusions including a discussion of the findings, limitations and managerial implications.

\section{Literature Review}

A stream of research has established the relationships between service orientation and overall job performance (c.f., Hogan \& Hogan, 1992) as well as 
service orientation and customer satisfaction (c.f., Carraher et al., 1998). Given the importance of service orientation, several studies have been conducted attempting to identify key antecedents and/or traits of this variable. Among the most significant works in the area of identifying service-oriented employees has been that of Hogan, Hogan, and Busch (1984). They defined service orientation as employees "disposition to be helpful, thoughtful, considerate and cooperative" (p.167).

From their definition of service-orientation, Hogan et al. (1984) developed the Service Orientation Index (SOI) that was derived from the Hogan Personality Inventory (HPI). The SOI consisted of 87 true-false items covering issues of agreeableness, adjustment, conscientiousness, and sociability. Validation of the SOI on a group of healthcare workers revealed a correlation of $\underline{r}=.31,(\underline{p}<.05)$ between SOI scores and service orientation ratings (Hogan \& Hogan, 1992; Hogan et al., 1984). Since that time, both the HPI and SOI have been altered so that the HPI currently is designed to measure the Big Five Personality Factors (Viswesvaran \& Ones, 2000) and contains 206 items (a 40 -item research version of the questionnaire is also available) and the SOI contains 14 items.

Since Hogan et al. (1984) performed their work on the service orientation construct, a number of consulting companies such as Personnel Decisions International., Questar Data Systems, and CORE Corporation have developed their own instruments to measure service orientation. These instruments are based on measures of attitudes and/or behaviorally-based personality questions. Unfortunately, research published in peer referred journals performed by individuals not employed by the consulting companies has yet to be presented on the efficacy of these instruments as these organizations are primarily interested in revenue generation rather than academic research and publication. An additional limitation of current measures of service orientation is their focus on cognitive abilities (Mitchell, 1997). Bowen, Siehl, \& Schneider (1989), on the other hand, have recommended the use of more "behaviorally based selection procedures" (p. 83) - such as biographical information blanks (Schneider, 1997) or biodata for short.

\section{Biographical Data}

Credit for the first modern use of biographical information in employee selection dates back to 1894 when T. L. Peters used biographical information for the selection of insurance agents (Ferguson, 1962). Research using biographical questionnaires in multiple-choice format blossomed during World War II, and much research was performed demonstrating that background items could predict success in the military (Parish \& Drucker, 1957). Crawford (1947) went as far as to examine the effectiveness of bomber crews and found that $83 \%$ of teams matched using biographical type information were judged to be effective teams which was nearly twice the success rate of teams designed by conventional means. Reviews of further work support the empirical validity of biographical data in predicting various criteria including job placement success (Harvey-Cook 
\& Taffler, 2000), turnover (Brush \& Owens, 1979), and performance for service employees in large organizations (Allworth \& Hesketh, 2000).

While biodata typically differ from measures of values, attitudes, moods, interests, personality, and abilities, it can assess constructs in all of these domains (Stokes, 1999). Biodata questions are often presented in a standardized self-report questionnaire with a multiple choice format that asks individuals to describe their past experiences, behaviors, feelings, and/or attitudes (Gatewood \& Field, 2001). For example, "in high school, how easy were your math classes?" is a biodata question that may reflect perceived cognitive ability while "in comparison with most people you know, how often do your friends come to you for advice or guidance" is a biodata question used to infer the personality construct of Agreeableness (Stokes, 1999). Researchers who use biodata assume that the best predictor of future behavior is past [and present] behaviors, attitudes, interests, and intentions (Owens, 1976; Stokes, 1999).

Schoenfeldt (1999) reported on several studies attempting to use empirically, factorially, and rationally derived biodata scales to predict service orientation in a concurrent validation strategy. Using responses from 867 service employees of a large communications organization and a 137-item biodata questionnaire constructed to measure 16 aspects of service delivery, he sought to predict supervisory ratings of service orientation. Schoenfelt (1999) found that service orientation could be predicted using biodata items. In particular, he found that service oriented employees honor commitments, are happy in both work situations and life in general, and have parents who were not overly involved in their lives. He also found that the factorially and rationally derived biodata scales did a better job of predicting the criterion of interest than the empirically derived scales.

Based upon the works of Hogan et al. (1984), Parasuraman, Zeithaml, and Berry (1985), Saxe and Weitz (1982), and Schoenfeldt (1999), McBride, Mendoza \& Carraher (1997) used samples of undergraduate students in order to create a more parsimonious biodata inventory purported to measure constructs related to service orientation. They developed a 39 -item biodata inventory hypothesized to contain the following seven topical scales: Life Satisfaction, Sociability, Agreeableness, Resistance to Stress, Responsibility, Need for Achievement, and desire to make Good Impressions on others. It was found that the Sociability and Good Impressions scales were significantly related to estimates of service orientation.

Carraher, Mendoza, Buckley, Schoenfeldt, and Carraher (1998) used four samples with a combined sample size of 861 in order to examine whether or not a modified version of the 39 item biodata instrument developed by McBride (1988, 1997; McBride et al., 1997) could be used to measure the service orientation construct. As a result, they developed a new version of the Need for Achievement scale and changed several items so that they all contained 5 response options - with the exception of sex and age. Using limited information factor analysis, Carraher et al. (1998) found that service orientation ratings 
were consistently related with three of the topical scales: Good Impression, Sociability, and Helpfulness.

Chait, Carraher, and Buckley (2000) used 605 subjects who were applicants for customer service positions with a large financial services organization to reexamine the relationship between the biodata measure and service orientation. Using a full profile principal components analysis, they found support for a five factor model with McBride's biodata instrument and further found that this five factor model was similar to the Big Five Personality factors of Extroversion, Conscientiousness, Emotional Stability, Agreeableness, and Openness to Experience.

More recently Carraher, Buckley, Scott, Parnell, \& Carraher (2002) used three samples of applicants for entry level customer service positions within a single global entrepreneurial information services organization with operations in the US, Canada, and the UK. They found it to be a useful screening device for selection decisions across all three countries.

In this study, we seek to extend the work of Chait et al. (2000) and examine if McBride's biodata instrument is useful within global entrepreneurial organizations (combining results from multiple countries within the same sample). However, unlike previous research, the current study does not focus on whether or not the job is perceived as that of a "typical" customer service representative. This is important since the goal here is to assess whether the instrument may also be of use with all current employees rather than just job applicants.

\section{Research Methodology}

\section{Subjects}

Subjects included 403 non-American employees from all organizational levels within a global entrepreneurial financial information services organization in the United Kingdom (England, Scotland, Wales, and Northern Ireland) and 295 non-American employees from another organization in Poland, Russia, and Ukraine. The gender composition of the first sample was $52 \%$ males and $48 \%$ females with the average age being $28.44(\mathrm{SD}=4.58)$ while it was $55 \%$ males and $45 \%$ females with the average age being $28.16(\mathrm{SD}=5.84)$ for the second sample.

\section{Instrument}

The primary instrument was the personality and biodata-oriented inventory developed by McBride (1988, 1997; McBride et al., 1997 [McBride et al. has a list of the items in an appendix]) as modified by Carraher et al. (1998). Using full-profile principal components analysis (as was used by Chait et al., 2000), we found support for the five-factor model. As a result, we are going to use the fivefactor model in this study with scales calculated using regressed factor scores. Due to problems with the use of coefficient alpha reliability estimates (Sethi \& Carraher, 1993), and the admonition that commonly used internal consistency 
estimations of reliabilities are "generally inappropriate for biodata" (Mitchell, 1994:492), we did not calculate them but supported the internal consistency of the scales using limited information factor analysis as suggested by Schoenfeldt and Mendoza (1994) and Mitchell (1994). Carraher et al. (2002) examined the 6-month test-retest reliability for the scales and found them to range from .7323 (Openness to Experience) to .8441 (Extroversion).

In terms of item content, in addition to covering basic demographics (age, sex, etc.), many of the questions contained in the inventory consisted of experiential, attitudinal, and behaviorally-based items (e.g. "When you were a member of a small group, how much do you participate?" and "How comfortable are you in new places and situations?"). The response formats for all questions except for age and gender had five response categories.

\section{Customer-Interaction Situation}

Subjects in the samples completed the questionnaire as part of the developmental process within their respective organizations. After completing the questionnaire subjects were scheduled to participate in the experimental task and informed that their performance would not influence their performance appraisals, merit raises, or threaten their jobs in any way. The assessment (described below) was designed by industrial psychologists and management professors involved in a larger project on the validation of selection and developmental procedures.

The experiential tasks were based upon detailed job analyses of customer service situations within the organization. Questions used in the assessment were gleaned from actual customer-employee interactions that had been video- and audio-taped. The organizations' chief executives/founders were interested in being able to use the questionnaire to identify which employees were in need of additional customer service training. The subjects were asked to role play the part of a telemarketing customer service representative who answered questions from customers about the firm's products (see Schoenfeldt, 1989; Schoenfeldt, Varca, Mendoza, \& Carraher, 1995).

Following the briefing period, each subject (one per session) was escorted to the experimental laboratory. The subject was seated at a desk with a telephone and given a catalog with descriptions of the services offered by the organization. Subjects were given time to familiarize themselves with the information and to situate themselves to the surroundings after which the "customer" (a confederate with a standard set of questions) called the subject. The "customer" then proceeded to ask the subject questions about the product. Subjects were debriefed and given personalized feedback about their biodata scores after the assessment.

\section{Criterion: Ratings of Service-orientation}

The telephone conversation between the customer and subject was recorded and later evaluated independently by three raters - including the owners of the 
organizations. Each rater had previously been trained in order to accurately and consistently identify differing levels of service-orientation. After listening to a conversation, raters would rate each of the subjects. Service-orientation was measured using a 17-item rater evaluation form consisting of items such as "The subject courteously and effectively dealt with customers" which were developed from the results of the job analyses performed by Schoenfeldt et al. (1995). Each rater assessed all of the subjects. As suggested by Tinsley and Weiss (1975), interrater reliabilities were assessed with corrected intraclass correlations from the rater evaluation forms for the three raters. The intraclass correlations were $\underline{\underline{r}}=.81$ for the first sample and $\underline{r}=.83$ for the second sample. These reliability estimates are comparable to those found by Hogan et al. (1984). The criterion scores were obtained by averaging the service-orientation scores given by the raters. This is similar to what Hogan et al. (1984), McBride (1988), Carraher et al. (1998), Chait et al. (2000); and Carraher et al. (2002) have previously done.

\section{Results}

As done in previous studies utilizing this scale, Pearson product-moment correlations between the criterion (the average composite measure of service orientation from the three raters) and each of the topical scales were examined as were the multiple $R$ 's regressing all five of the scales on the criterion. The results of these analyses are presented in Table 1.

Focusing on the results of the correlations, we found that the Extroversion, Agreeableness, Openness to Experience and Conscientiousness scales have the highest correlations with ratings on service-orientation for both samples. It is interesting to note that the overall correlations tend to be stronger in the Central European samples than the Western European sample. This may be because of the more clear relationship between pay and performance in the Central European organization (Allen \& Helms, 2002) as the labor laws allow the organization a greater degree of latitude in hiring and firing employees than in Western Europe.

Additionally it should be noted that the coefficients found here are similar to those found by Hogan et al. (1984), Personnel Decisions Inc., (Paajanen, 1995), and CORE Corporation (Fogli, 1995) with other measures of service-orientation and the owners of the organizations personally agreed with the ratings. CORE Corporation reports that their measures of service-orientation have validity coefficients in the range of .19 to .36 for the service-oriented performance of tellers in the banking industry (undated) and Personnel Decisions International report validity coefficients in the range of .19 to .32 across a variety of occupations for their measure of service-orientation (McLellan \& Paajanen, 1994). Carraher et al. $(1998 ; 2002)$ found Multiple R's between .42 to .56 for customer service employees. 
Table 1

Correlations of Service-Orientation with Biodata Scales

\begin{tabular}{|c|c|c|}
\hline \multirow[t]{2}{*}{ Scales } & \multicolumn{2}{|c|}{ Correlation with Criterion } \\
\hline & Central Europe & Western Europe \\
\hline Extroversion & $.40^{k * *}$ & $.22^{* * *}$ \\
\hline Agreeableness & $.29^{+* *}$ & $.13^{* *}$ \\
\hline Emotional Stability & .10 & .07 \\
\hline Conscientiousness & $.29^{* * *}$ & $.10^{*}$ \\
\hline Openness to Experience & $.35^{* * *}$ & $.16^{* * *}$ \\
\hline $\begin{array}{l}\text { Multiple } \mathrm{R} \text { from regression } \\
\text { analysis including } 5 \text { topical scales }\end{array}$ & $.50^{* * *}$ & $.37^{* * *}$ \\
\hline R Squared & .25 & .14 \\
\hline
\end{tabular}

${ }^{*}=\mathbf{p}<.05 ;{ }^{* *}=\mathrm{p}<.01 ;{ }^{\cdots *}=\mathbf{p}<.001$

\section{Conclusions}

The findings here suggest that service-orientation can be effectively identified using a biodata inventory such as the one used in this study. More importantly, we found that biodata inventory can also be used within organizations for all levels of employees. These findings are consistent with those found by previous researchers (Carraher et al. 1998; 2002) suggesting that this instrument may be useful with job applicants for selection purposes. The instrument can also be utilized for developmental purposes in order to determine which organizational employees may benefit from customer service training.

Given the size and nature of the organizations sampled in this study, the findings regarding the potential of using biodata to pinpoint customer service orientation is particularly critical. As O'Gorman and Doran (1999) emphasized, it is through the focus on serving the customer well that small and medium sized businesses may more effectively compete with larger organizations that may have the cost advantage (Meters \& Ketzenberg, 2000).

The results of the current study clearly show service orientation to be reflective of extroverted individuals who make a conscious effort to actively help others and seek out new ways to satisfy the needs of customers. As a consequence, it does appear that inventories such as the one utilized in this study may serve as useful screening devices for identifying individuals with the tendency to exhibit strong service oriented behaviors for both developmental and selection purposes and therefore we suggest that practicing managers make use of instruments such as this one in their hiring decisions when seeking to hire customer service oriented employees. 
While the identification of proactive, considerate employees may be important to any organization, it is especially crucial in ones in which customer service may be a major part of the job for most of the positions within the organization as is increasingly becoming the case in the United States and around much of the world - and as is especially important in entrepreneurial businesses where most employees may be called upon on a consistent basis to interact with both internal and external customers. Moreover, the generalizability of the instruments used to tap the construct is enhanced by the concept of service orientation itself. That is, it is not occupation specific and as shown here may be used across all levels of an organization - making it especially useful in general selection decisions.

It should be noted that the current study is limited in its scope as only individuals from the UK, Poland, Ukraine, and Russia within a single industry were sampled and while based upon actual customer service interactions, the behavioral exercise was simulated. In the future we would like to see research done examining actual customer service interactions performed across an even wider number of countries. It might also prove useful to perform validation studies within organizations using both predictive and concurrent validation strategies in order to see how comparable the results may be.

This research has served to shed light on those areas of service orientation that may be most important in the identification of individuals likely to behave in a service-oriented manner. Knowing which factors are important is a significant asset in developing a program designed to increase the service orientation of both new and existing employees. In fact, in positions where service orientation may be important, individuals should be selected based upon the degree to which they possess these characteristics and are likely to utilize them in the context of the position itself. Therefore, we believe that the biodata data inventory instrument utilized here can make an important contribution in the identification of individuals across occupations likely to exhibit high levels of service-oriented behaviors whether for selection or developmental purposes and therefore likely to increase the perceived service quality for the organization (Duffy, Duffy, \& Kilbourne, 2001).

\section{References}

Allen, R. \& Helms, M. (2002). Employee perceptions of the relationship between strategy, rewards, and organizational performance. Iournal of Business Strategies, 19 (2), $115-140$.

Allworth, J. \& Hesketh, B. (2000). Job requirements biodata as a predictor of performance in customer service roles. International Journal of Selection and Assessment, $\underline{8}(3), 137-147$.

Becherer, R. \& Maurer, J. (1999). The proactive personality disposition and entrepreneurial behavior among small company presidents. Journal of Small Business Management, 37 (1), 28-36. 
Bowen, D.E., Siehl, C. \& Schneider, B. (1989). A framework for analyzing customer service orientations in manufacturing. Academy of Management Review, 14, 75-95.

Brush, D. \& Owens, W. (1979). Implementation and evaluation of an assessment classification model for manpower utilization. Personnel Psychology, 32, 369-383.

Carraher, S.M. \& Hart, D. (1995). Theory and measurement of customer service-orientation. Symposium presented at the annual meeting of the Society for Industrial and Organizational Psychology, Orlando.

Carraher, S.M., Mendoza, J., Buckley, M.R., Schoenfeldt, L., \& Carraher, C. (1998). Validation of an instrument to measure service orientation. Journal of Quality Management, $\underline{3}$ (2), $211-224$.

Carraher, S., Buckley, M., Scott, C., Parnell, J. \& Carraher, C. (2002). Customer service selection with biodata in a global entrepreneurial information services organization. Journal of Applied Management \& Entrepreneurship, 7 (2) 45-55.

Carrier. C. (1999). The training and development needs of owner-managers of small businesses with export potential. Journal of Small Business Management, 37 (4), $30-41$.

Chait, H., Carraher, S.M., \& Buckley, M.R. (2000). Measuring service orientation with biodata. Journal of Managerial Issues, 12 (1), 109-120.

CORE Corporation undated. CORE corporation's customer service testing. Pleasant Hill, CA: Author.

Craw ford, M. (1947). Psychological research on operational training in the continental Air Forces. (Research Report No. 16). Army Air Forces Aviation Psychology program.

Duffy, J., Duffy, M., \& Kilbourne, W. (2001). A comparative study of resident, family, and administrator expectations for service quality in long-term care facilities. Health Care Management Review. 26 (3), 75-85.

Ferguson, L.W. (1962). The heritage of industrial psychology. Hartford, CT: Author.

Fogli, L. (1995). Construct validity of ServiceFirst from CORE corporation. Paper presented at the annual meeting of the Society for Industrial and Organizational Psychology, Orlando.

Gatewood, R. \& Field, H. (2001). Human Resource Selection $5^{\mathrm{t}_{1}}$ Ed. Harcourt College P.: Fort Worth.

Harvey-Cook, J. \& Taffler, R. (2000). Biodata in professional entry-level selection: Statistical scoring of common format applications. Journal of Occupational \& Organizational Psychology, 73 (1), 103-118. 
Hipkin, I. (2000). TQM: The paradox of empowerment and conformance in the service sector. South African Journal of Business Management, 31 (1), 1-8.

Hogan, R., \& Hogan, J. (1992). Hogan personality inventory manual. Tulsa: Hogan Assessment Systems.

Hogan, R., Hogan, J., \& Busch, C. (1984). How to measure service orientation. Journal of Applied Psychology, 69, 167-173.

Hui, C., Lam, S., \& Schaubroeck, J. (2001). Can good citizens lead the way in providing quality service? A field quasi experiment. Academy of Management Journal,44 (5) 988-995.

Martin, C. (2000). Acid tests of employees' customer service orientation. Journal of Services Marketing, 14 (2), 90-91.

McBride, A. (1988). The development of a service orientation employee selection instrument. Unpublished masters thesis, Texas A \& M University.

McBride, A. (1997). When is biodata not biodata? Southern Management Association Proceedings, 302-304.

McBride, A., Mendoza, J., \& Carraher, S. (1997). Development of a biodata index to measure service-orientation. Psychological Reports, 81, 1395-1407.

McLellan, R.A. \& Paajanen, G.E. (1994). PDI customer service inventory manual. Minneapolis: PDI.

McWilliams, A., Van Fleet, D., \& Wright, P. (2001). Strategic management of human resources for global competitive advantage. Journal of Business Strategies, 18 (1), $1-24$.

Metters, R. \& Ketzenberg, M. (2000). Small is beautiful: The re-emergence of the convenience strategy. Journal of Business Strategies, 17 (1), 25-36.

Mitchell, T. (1994). The utility of biodata. In Biodata Handbook. Eds. G. Stokes, M. Mumford, \& W. Owens. Palo Alto, CA: CPP.

Mitchell, T. (1997). Biodata for customer service performance: Do nice guys finish last? Paper presented at the 12th meeting of the Society for Industrial and Organizational Psychology, St. Louis.

O'Gorman, C. \& Doran, R. (1999). Mission statements in small and medium-sized businesses. Journal of Small Business Management, 37 (4), 59-67.

Owens, W. (1976). Background data. In Handbook of Industrial and Organizational Psychology ed. Marvin Dunnette. Chicago: Rand McNally. 
Paajanen, G. (1995). Construct validity of the PDI customer service inventory. Paper presented at the annual meeting of the Society of Industrial and Organizational Psychology, Orlando.

Parasuraman, A., Zeithaml, V., \& Berry, L. (1985). A conceptual model of service quality and its implications for future research. Journal of Marketing, 49, 41-50.

Parish, J. \& Drucker, A. (1957). Personnel research of Officer Candidate School, USA TAGO Personnel Research Branch Technical Research Report. No. 117.

Pugh, S. (2001). Service with a smile: Emotional contagion in the service encounter. Academy of Management Journal, 44 (5), 1018-1027.

Robertson, P. (1995). Involvement in boundry-spanning activity: Mitigating the relationship between work setting and behavior. Journal of Public Administration Research \& Theory, $\underline{5}$ (1), 73-98.

Saxe, R. \& Weitz, B. (1982). The SOCO scale: A measure of the customer orientation of salespeople. Journal of Marketing Research, 19, 343-351.

Schneider, B. (1997). Customer service-orientation: Predictive validity and beyond Discussants comments for symposium presented at the 12th meeting of the Society for Industrial and Organizational Psychology, St. Louis.

Schoenfeldt, L. (1989). Biographical data as the new frontier of employee selection research. Presented at the annual meeting of the American Psychological Association, New Orleans, LA.

Schoenfeldt. L. (1999). From dust bowl empiricism to rational constructs in biographical data. Human Resource Management Review, 9 (2), 147-167.

Schoenfeldt., L. \& Mendoza, J. (1994). Developing and using factorially derived biographical scales. In Biodata Handbook Eds. G. Stokes, M. Mumford, \& W. Owens. Palo Alto, CA: CPP.

Schoenfeldt, L.F., Varca, P.E., Mendoza, J.L. \& Carraher, S.M. (1995). Selecting serviceoriented employees with biodata. Paper presented at the annual meeting of the Society for Industrial \& Organizational Psychology, Orlando.

Sethi, V. \& Carraher, S.M. (1993). Developing measures for assessing the organizational impact of information technology: A comment on Mahmood and Soon's paper. Decision Sciences, 24, 867-877.

Stokes, G. (1999). Introduction to special issue: The next one hundred years of biodata. Human Resources Management Review, 99 (9), $111-116$.

Tinsley, H.E. \& Weiss, D.J. (1975). Interrater reliability and agreement of subjective judgements. Journal of Counseling Psychology, 22, 358-376. 
Viswesvaran, C.\& Ones, D. (2000). Measurement error in ABig Five Factors@ personality assessment: Reliability generalization across studies and measures. Educational and Psychological Measurement, 60 (2), 224-235.

Waldman, D. A. \& Gopalakrishnan, M. (1996). Operational, organizational, and human resource factors predictive of customer perceptions of service quality. Journal of Quality Management, 1, 91-107.

Wright, N., Pearce, J., \& Busbin, J. (1997). Linking customer service orientation to competitive performance: Does the marketing concept really work? Journal of Marketing Theory and Practice, 5 (4), 23-33.

Zinger, J., LeBrasseur, R., \& Zanibbi, L. (2001). Factors influencing early stage performance in Canadian microenterprises. Journal of Developmental Entrepreneurship, $\underline{6}(2), 129-150$.

Shawn M. Carraher received his $\mathrm{Ph}$. D. in Business Administration from the University of Oklahoma. He is the Virginia Brewczynski Endowed Chair in Entrepreneurial Studies, Director of the Center for Emerging Technology \& Entrepreneurial Studies, Head of Entrepreneurial Studies, and Director of the Small Business Institute at Cameron University. His primary research interests combine Strategic Management, International Management, Human Resources/ Organizational Behavior, and Entrepreneurship in order to examine cross-cultural differences in compensation, selection, and staffing within entrepreneurial organizations. His recent publications have appeared in the Journal of Applied Psychology, Decision Sciences, Educational and Psychological Measurement, Journal of Managerial Issues, Journal of Vocational Behavior, Journal of Quality Management, Journal of Applied Management and Entrepreneurship, Journal of Business \& Entrepreneurship, Global Business and Finance Review, and the Journal of Business Strategies.

Sarah C. Carraher has degrees in History and Music performance and is owner of Consolidation Enterprises. She has done research on expatriate stress, customer service orientation, work norms among global entrepreneurs, and the application of equity theory to global entrepreneurs. Her previous research has been published in the Academy of Entrepreneurship Journal, International Journal of Family Business, and the Journal of Small Business Strategy.

Alma Mintu-Wimsatt is a professor of marketing at Texas A\&M UniversityCommerce. She received her Ph.D. from the University in Kentucky. Her areas of research interest are cross-cultural negotiations, buyer-seller interaction and teaching pedagogy focusing on technology mediated learning. Her research works have been published in Management Science, Journal of the Academy of Marketing Science, Thunderbird International Business Review, Journal of 
Personal Selling and Sales Management, International Journal of Research in Marketing, European Journal of Marketing, Journal of Business and Industrial Marketing, and Marketing Education Review, to name a few. 